\title{
Daughter cyst sign in the congenital ovarian cyst
}

\author{
Priya Singh, Surya Pratap Singh, Hira Lal
}

Radiodiagnosis, Sanjay Gandhi Post Graduate Institute of Medical Sciences, Lucknow, Uttar Pradesh, India

\section{Correspondence to Dr Hira Lal; \\ hiralal2007@yahoo.co.in}

Accepted 12 May 2021

\section{DESCRIPTION}

Congenital ovarian cyst is the most common cause of abdominal mass in a female fetus. ${ }^{1}$ The ovarian cyst usually presents in a female fetus in the third trimester under the influence of maternal hormones. ${ }^{2}$ Ovarian cysts of more than $20 \mathrm{~mm}$ are considered pathological. ${ }^{2}$ They can be simple or complex. Simple cysts are more common, have a thin-walled unilocular appearance, while complex cysts have a multiseptated appearance. ${ }^{2}$ Most ovarian cysts regress with time and do not require surgery. ${ }^{3}$ However, complicated/complex cyst, large cyst producing pressure symptoms over adjacent organs and cyst that fail to regress after 6 months needs surgical resection. ${ }^{3}$ Differentials of fetal or neonatal cystic abdominopelvic lesions include enteric duplication cyst, choledochal cyst, lymphangioma, dilated bowel, cystic neuroblastoma, urinoma, dilated renal pelvicalyceal system, urachal anomalies, dermoid cyst, hydrocolpos and ovarian cyst. Therefore, differentiating ovarian cyst from other cystic masses is clinically important for management.

Daughter cyst sign (figure 1) refers to an eccentric smaller cyst within a large cyst on ultrasonography (USG). This sign is almost pathognomonic of congenital ovarian cyst with a reported sensitivity of $82 \%$, specificity and positive predictive value of $100 \% .^{45}$ Pathologically, the daughter cyst sign represents a follicle within an ovarian cyst. Not all congenital ovarian cysts show daughter cyst sign, but the presence of daughter cyst sign on USG in female fetus or neonates excludes other differentials of cystic abdominal-pelvic mass. Daughter cyst sign is also commonly described in the setting of hydatid cyst, which is unusual in neonatal/infantile life, commonly intrahepatic and on USG, their daughter cyst is hypoechoic or anechoic compared with the

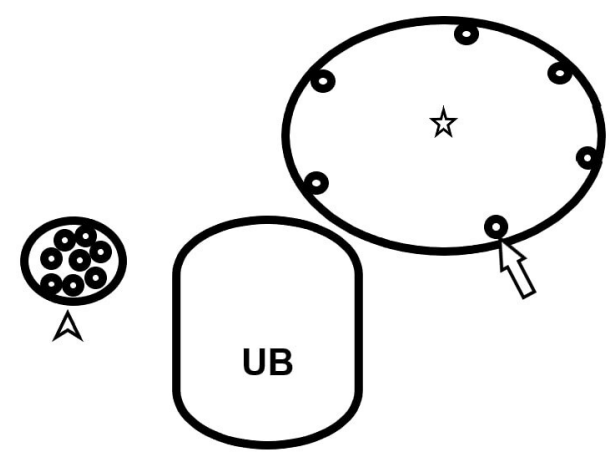

Figure 1 Schematic diagram of daughter cyst sign shows the eccentric daughter cyst (arrow) within large mother ovarian cyst (star). Urinary bladder (UB), normal right ovary (arrowhead).

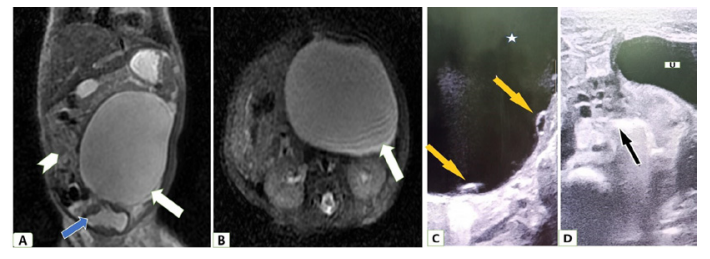

Figure 2 (A,B) MRI. (A) T2-weighted coronal and (B) T2-weighted axial images show a well-defined ovalshaped thin-walled unilocular large cystic pelvic mass (white arrow) towards the left. The mass was superior to the bladder (blue arrow), cranially extending to the lumbar region and crossing the midline. Small bowel loops are displaced towards the right by the mass (white arrowhead). (C,D) High-resolution ultrasound (HRUSG). (C) HRUSG of the cystic mass in the left abdominalpelvic region shows two small eccentric cysts (yellow arrows) within the large cyst (star), producing daughter cyst sign. (D) HRUSG shows a normal right ovary (black arrow) having few small follicles while left ovary is not visualised. U, urinary bladder.

solid appearance of mother cyst. Serology further confirms the diagnosis of a hydatid cyst.

A 3-day-old girl child was diagnosed with an abdominopelvic cyst on antenatal USG done in the third trimester. She was delivered by caesarean section without any perinatal complications. Differentials of cystic genitourinary mass, gastrointestinal mass and lymphangioma were kept. For further characterisation of cystic mass, MRI (figure 2A,B) was done, which revealed a well-circumscribed large $6.5 \times 6.4 \times 7 \mathrm{~cm}$ cystic mass in the pelvis towards the left side. The wall of the cystic lesion was smooth and thin with no solid enhancing component. Fat planes with adjacent organs (urinary bladder, bowel and kidneys) were well maintained. Bilateral ovaries

\section{Patient's perspective}

Patient's mother-During my routine antenatal ultrasound, the doctor told me that my child has a fluid-filled abdominal mass. We were very much worried about our child. However, doctors reassured us that they would investigate and treat this mass after the child's birth. After being born, my girl child has no other problem except for mild abdominal distension. After few investigations, they finally concluded that this cyst was arising from her ovary. However, they told us that this cyst is not worrisome and it will regress spontaneously, and does not require surgery. I was delighted to know this. Presently she is on regular ultrasound follow-up, and her abdominal distension is gradually decreasing. 


\section{Learning points}

Apart from the well-described daughter cyst sign of hydatid cyst, it may also be seen in a congenital ovarian cyst.

- Not all congenital ovarian cyst shows daughter cyst sign. Thus, the absence of this sign does not exclude the possibility of ovarian cyst.

- A careful evaluation with high-resolution ultrasound to look for daughter cyst sign and the absence of an ipsilateral ovary should be done in a female fetus, neonate or infant having cystic pelvic mass to rule out ovarian cyst before proceeding for any further investigation.

could not be visualised on MRI. As no definite organ of origin of the cystic mass could be identified on MRI and to localise bilateral ovaries, a high-resolution USG (HRUSG) was done using a linear 7.5-11 MHz probe. HRUSG (figure 2C,D) revealed a normal right ovary with few small follicles and non-visualisation of the left ovary. Few small less than $0.5 \mathrm{~cm}$ eccentric cysts were seen along the wall of the large left abdominopelvic cystic lesion producing daughter cyst sign. Thus, a diagnosis of the congenital left ovarian cyst was made. She was kept on close follow-up. On follow-up USG after 1 month, a decrease in size of the cyst was seen.
Acknowledgements We would like to thank Mrs Manju Singh for coordinating in the image collection.

Contributors This report was supervised by HL. Data was compiled and written by PS. The manuscript review was done by SPS.

Funding The authors have not declared a specific grant for this research from any funding agency in the public, commercial or not-for-profit sectors.

Competing interests None declared.

Patient consent for publication Obtained

Provenance and peer review Not commissioned; externally peer reviewed.

\section{ORCID iD}

Hira Lal http://orcid.org/0000-0001-7957-635X

\section{REFERENCES}

1 Akın MA, Akın L, Özbek S, et al. Fetal-neonatal ovarian cysts--their monitoring and management: retrospective evaluation of 20 cases and review of the literature. J Clin Res Pediatr Endocrinol 2010;2:28-33.

2 Trinh TW, Kennedy AM. Fetal ovarian cysts: review of imaging spectrum, differential diagnosis, management, and outcome. Radiographics 2015;35:621-35.

3 Brandt ML, Luks Fl, Filiatrault D, et al. Surgical indications in antenatally diagnosed ovarian cysts. J Pediatr Surg 1991;26:276-82.

4 Quarello E, Gorincour G, Merrot T, et al. The 'daughter cyst sign': a sonographic clue to the diagnosis of fetal ovarian cyst. Ultrasound Obstet Gynecol 2003:22:433-4.

5 Lee H-J, Woo S-K, Kim J-S, et al. "Daughter Cyst" Sign. Am J Roentgenol $2000 ; 174: 1013-5$

Copyright 2021 BMJ Publishing Group. All rights reserved. For permission to reuse any of this content visit

https://www.bmj.com/company/products-services/rights-and-licensing/permissions/

BMJ Case Report Fellows may re-use this article for personal use and teaching without any further permission.

Become a Fellow of BMJ Case Reports today and you can:

- Submit as many cases as you like

- Enjoy fast sympathetic peer review and rapid publication of accepted articles

- Access all the published articles

Re-use any of the published material for personal use and teaching without further permission

Customer Service

If you have any further queries about your subscription, please contact our customer services team on +44 (0) 2071111105 or via email at support@bmj.com.

Visit casereports.bmj.com for more articles like this and to become a Fellow 